
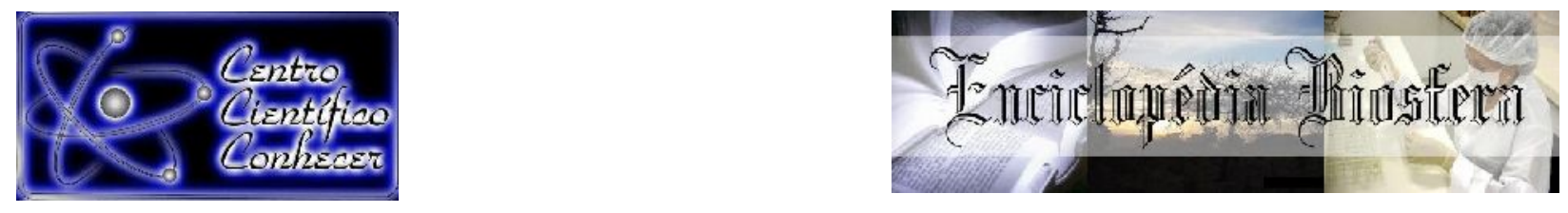

\title{
ASPECTOS REPRODUTIVOS DO MILHO HÍBRIDO SIMPLES 2B810 PW (Dow) (Zea mays L.) CULTIVADO EM ALTA FLORESTA, MATO GROSSO
}

Geysla Carla Lopes dos Santos ${ }^{1}$; Eliane Cristina Moreno de Pedri'; Alex Souza Rodrigues $^{3}$; Guilherme Ferreira Pena ${ }^{4}$; Ana Aparecida Bandini Rossi ${ }^{5}$

${ }^{1}$ Graduanda em Licenciatura e Bacharelado em Ciências Biológicas, Universidade do Estado de Mato Grosso (UNEMAT), Alta Floresta-MT, Brasil

E-mail: geysla_carla@hotmail.com

${ }^{2}$ Doutoranda em Biodiversidade e Biotecnologia (PPG-Bionorte), Universidade do

Estado de Mato Grosso (UNEMAT), Alta Floresta-MT, Brasil

${ }^{3}$ Biólogo, Universidade do Estado de Mato Grosso (UNEMAT), Alta Floresta-MT, Brasil

${ }^{4}$ Professor visitante da Universidade do Estado de Mato Grosso (UNEMAT), Alta

Floresta-MT, Brasil

${ }^{5}$ Professora efetiva da Universidade do Estado de Mato Grosso (UNEMAT), Alta Floresta-MT, Brasil

Recebido em: 06/04/2019 - Aprovado em: 10/06/2019 - Publicado em: 30/06/2019 DOI: 10.18677/EnciBio_2019A20

\begin{abstract}
RESUMO
O milho (Zea mays L.) é uma gramínea da família Poaceae que, embora tenha, respectivamente, seus centros de origem e diversidade no México e na América, é uma espécie cultivada em todo mundo. A cultura apresenta importante papel na produção agrícola do país e sua utilização vai desde a alimentação animal até a indústria de alta tecnologia. Pesquisas relacionadas aos aspectos reprodutivos de um organismo permitem obter resultados que podem ser aplicados em estudos de genética de populações, na conservação dos recursos vegetais e em programas de melhoramento. Diante disso, objetivou-se neste trabalho avaliar os aspectos reprodutivos do híbrido simples 2B810 PW (Dow) (Zea mays) por meio do índice meiótico e viabilidade polínica. O material vegetal foi coletado no município de Alta Floresta, Mato Grosso. Para análise do índice meiótico (IM) foram coletados botões florais em diferentes estágios de desenvolvimento e para a estimativa da viabilidade polínica foram coletados, pela manhã, botões florais em pré-antese. Para análise do IM, as lâminas foram coradas com orceína acética $2 \%$ e para estimar a viabilidade polínica foram utilizados os corantes reativo de Alexander, carmim acético, lugol e sudan IV. A análise dos resultados indicou índice meiótico de $85 \%$. A viabilidade polínica da espécie foi satisfatória com médias acima de 95\%. Portanto, conclui-se que os quatro corantes utilizados foram eficientes para estimar a viabilidade polínica do hibrido simples 2B810 PW (Dow) (Zea mays) e a espécie apresenta padrão meiótico normal.
\end{abstract}

PALAVRAS-CHAVE: biologia reprodutiva, Poaceae, pólen. 


\title{
REPRODUCTIVE ASPECTS OF SIMPLE HYBRID MAIZE 2B810 PW (Dow) (Zea mays L.) CULTIVATED IN ALTA FLORESTA, MATO GROSSO
}

\begin{abstract}
Maize (Zea mays L.) is a grass of the Poaceae family that, although it has, respectively, its centers of origin and diversity in Mexico and America, is a species cultivated worldwide. The culture plays an important role in the agricultural production of the country and its use goes from animal feed to the high technology industry. Research related to the reproductive aspects of an organism allows to obtain results that can be applied in studies of population genetics, in the conservation of vegetal resources and in breeding programs. The objective of this work was to evaluate the reproductive aspects of the simple hybrid 2B810 PW (Dow) (Zea mays) through the meiotic index and pollen viability. The plant material was collected in the municipality of Alta Floresta, Mato Grosso. For the analysis of the meiotic index (IM), floral buds were collected at different stages of development and, for the estimation of pollen viability, pre-anthesis flower buds were collected in the morning. For IM analysis, the slides were stained with $2 \%$ acetic orcein and the reactive dyes from Alexander, acetic carmine, lugol and sudan IV were used to estimate pollen viability. To evaluate the pollen viability, the reactive dyes of Alexander, acetic carmine, lugol and sudan IV were used. Analysis of the results indicated a meiotic index of $85 \%$. The pollen viability of the species was satisfactory with means above $95 \%$. Therefore, it is concluded that the four dyes used were efficient to estimate the polynomial viability of the simple hybrid 2B810 PW (Dow) (Zea mays) and the species presents normal meiotic pattern.
\end{abstract}

KEYWORDS: reproductive biology, Poaceae, pollen.

\section{INTRODUÇÃO}

O milho (Zea mays L.) é uma gramínea da família Poaceae que, embora não seja endêmico do Brasil, apresenta ampla distribuição nos estados brasileiros (FLORA DO BRASIL 2020, em construção). A cultura é utilizada como fonte de alimento para humanos, ração animal e como matéria-prima para indústrias. Além disso, o milho tem importante papel na rotação de culturas, possibilitando a melhoria e a conservação do solo e da matéria orgânica, além de promover incremento da produtividade nas culturas subsequentes (FAVARATO et al., 2016).

De acordo com a safra 2017/18, o Brasil é o terceiro maior produtor de milho no mundo (95,0 milhões de toneladas), ficando atrás dos EUA (370,3 mi t) e da China (215,0 mi t), respectivamente (USDA, 2018). A maior produção de milho no Brasil esta na região Centro-Oeste onde, de acordo com a safra 2017/18, foram colhidas 41,45 milhões de toneladas (CONAB, 2018). No estado de Mato Grosso, para a safra 2018/19, é esperada uma produção de 25,5 milhões de toneladas, um incremento de 3,43\% (IMEA, 2018), sendo que na região o grão é difundido em alimentos (cereais) e produtos em gerais, contudo, é utilizado principalmente em rações (aves, bovinos e suínos) e na produção de etanol (JORNALISMO AGROPECUÁRIO, 2015).

O milho é uma espécie monoica, sendo a inflorescência masculina denominada de pendão e a feminina de espiga. As plantas do milho são alógamas e geralmente protândrica, isto é, o órgão masculino está apto para a fecundação antes do feminino, favorecendo assim o mecanismo de polinização cruzada. A panícula, que forma as flores masculinas, pode atingir de 50 a $60 \mathrm{~cm}$ de comprimento e a coloração pode variar de verde a vermelho escuro. As flores do milho são formadas 
por três estames e são necessários, aproximadamente, oito dias para a formação dos pólens, sendo que cada inflorescência pode produzir, aproximadamente, 50 milhões de grãos de pólen (BARROS; CALADO, 2014).

$O$ pólen é um dos materiais genéticos mais utilizados em pesquisas relacionadas ao melhoramento genético, por isso, estudos relacionados à estimativa da viabilidade polínica vêm sendo realizados com espécies cultivadas (TIAGO et al., 2014: SANTOS et al., 2015; QUEIROZ et al., 2018). A viabilidade polínica é uma medida de fertilidade masculina que pode ser determinada pelo método indireto baseado em parâmetros citológicos como a coloração (ALMEIDA et al., 2011).

O uso de corantes para estimar a viabilidade do pólen é um método muito utilizado, especialmente pela simplicidade e rapidez na obtenção dos resultados (DAVIDE et al., 2009). A técnica permite a seleção de espécies vegetais com características promissoras para uso em programas de melhoramento genético (HISTER et al., 2016; BRAMBATTI et al., 2016). Diante disso, objetivou-se neste estudo analisar o índice meiótico e estimar a viabilidade polínica do híbrido simples 2B810 PW (Dow) (Zea mays) por meio de testes colorimétricos.

\section{MATERIAL E MÉTODOS}

O estudo foi realizado no Laboratório de Genética Vegetal e Biologia Molecular (GenBioMol) da Universidade do Estado de Mato Grosso (UNEMAT), Campus de Alta Floresta, MT. Os botões florais do híbrido simples 2B810 PW (Dow) foram coletados em um plantio localizado no campo experimental da UNEMAT/AF, Campus II (Figura 1A), 60 dias após o plantio.

Para análise do índice meiótico (IM) foram coletados botões florais em diferentes estágios de desenvolvimento e para a estimativa da viabilidade polínica foram coletados, pela manhã, botões florais em pré-antese (Figura 1B), fixados em Carnoy (3:1 - álcool absoluto: ácido acético) por 24 horas e, posteriormente, transferidos para álcool $70 \%$ e armazenados em freezer $( \pm 4 \stackrel{\circ}{ }$ ) $)$, até o momento do preparo das lâminas.

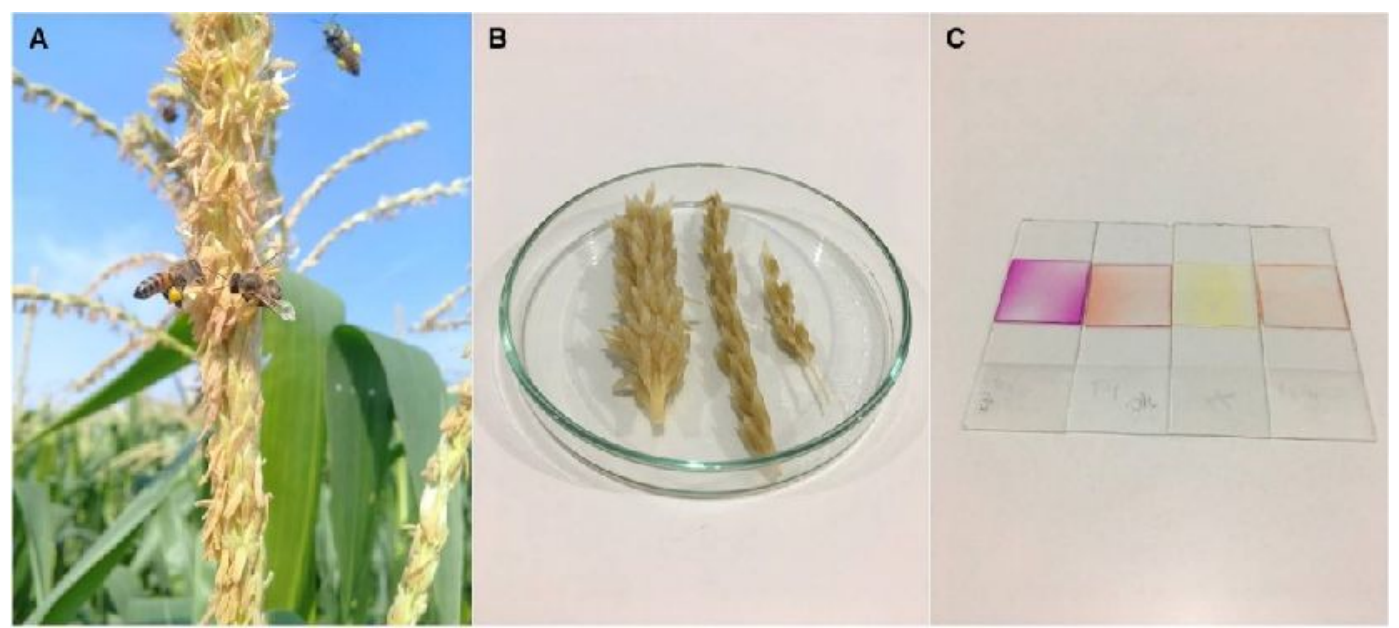

FIGURA 1 - Híbrido simples 2B810 PW (Dow) (Zea mays). (A) Botões florais; (B) Botões florais coletados em pré-antese; (C) Lâminas confeccionadas para estimativa da viabilidade polínica. Fonte: os autores.

Para análise do índice meiótico foram preparadas oito lâminas utilizando o método de esmagamento da antera (GUERRA; SOUZA, 2002), onde a cápsula se 
rompe e ocorre a liberação do pólen facilitando a observação das células em estágio de pós-meiose. Posteriormente, o material foi corado com orceína acética $2 \%$ e observado em microscópio óptico, magnitude de 400X, sendo contabilizadas 300 células por lâmina, totalizando 2400 produtos pós-meiótico. O índice meiótico foi calculado pela equação 1:

$$
\operatorname{IM}(\%)=\left(\frac{T}{N}\right) \times 100
$$

A viabilidade polínica foi estimada via reativo de Alexander, carmim acético $2 \%$, lugol e sudan IV, e, para o preparo das lâminas, as anteras foram cortadas transversalmente com o auxílio de um bisturi e, em seguida, esmagadas com bastão de vidro, visando à liberação dos grãos de pólen sobre $20 \mu \mathrm{L}$ de corante (GUERRA; SOUZA, 2002). Após a retirada dos debris, o material foi coberto com uma lamínula e visualizado ao microscópio (Figura 1C). Para cada corante foram preparadas oito lâminas, sendo contados 300 grãos de pólen/lâmina, totalizando 2400 grãos de pólen por corante. A contagem ao acaso dos grãos de pólen corados foi realizada pelo método de varredura, em microscópio ótico, magnitude de 400X. A porcentagem de grãos de polens viáveis foi realizada de acordo com a equação 2 :

$$
\text { Viabilidade do pólen }(\%)=\frac{\mathbb{N}^{2} \text { de grăos de pólen corados }}{\mathbb{N}^{2} \text { de grãos de pólen total }} \times 100
$$

Os dados de viabilidade polínica foram submetidos à análise de variância (ANOVA) e as médias comparadas pelo teste de Tukey a $5 \%$ de probabilidade utilizando o programa estatístico Genes, versão 2018.23 (CRUZ, 2013).

\section{RESULTADOS E DISCUSSÃO}

Os produtos pós-meióticos do híbrido simples 2B810 PW (Dow) (Zea mays) foram encontrados em botões florais com comprimento entre 7,71-8,70 $\mathrm{mm}$ (média $=$ $7,93 \pm 0,45 \mathrm{~mm}$ ) (Figura $2 \mathrm{~A}$ ) e os botões com comprimento entre 10,55-11,88 (média $=10,95 \pm 0,56 \mathrm{~mm}$ ) já apresentavam pólen (Figura 2B).

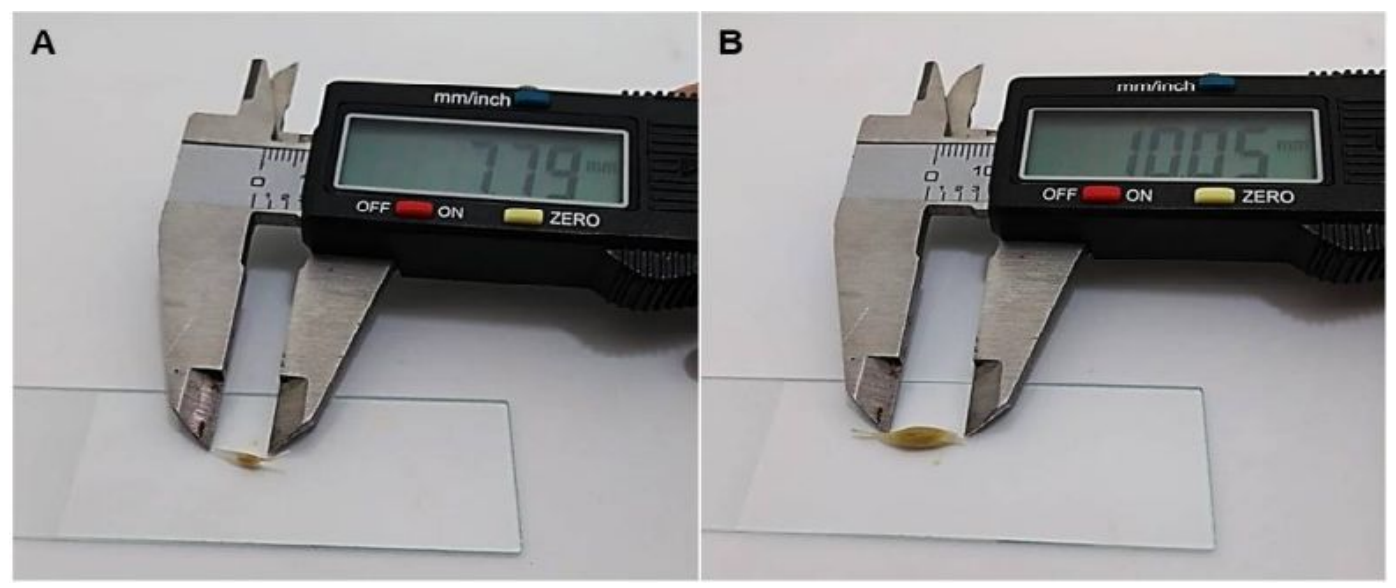

FIGURA 2 - Híbrido simples 2B810 PW (Dow) (Zea mays). Mensuração do botão floral para pós-meiótico (A) e para a estimativa da viabilidade polínica (B) com auxílio de paquímetro digital. Fonte: os autores. 
O índice meiótico é um dado complementar e um indicador de regularidade (LOVE, 1949). Neste estudo foram observadas células normais (tétrade) e anormais (mônode, díade e tríade) (Figura 3). A espécie apresentou IM médio de $85 \%$ e segundo Love (1949) plantas com IM superior a 80\% são considerados estáveis e satisfatórios, logo, os resultados obtidos neste estudo evidenciam regularidade meiótica nas amostras analisadas. Pagliarini (2000) destaca ainda que o processo normal da meiose garante a viabilidade do gameta e irregularidades podem resultar em produtos pós-meióticos anormais, ou seja, na infertilidade da planta.

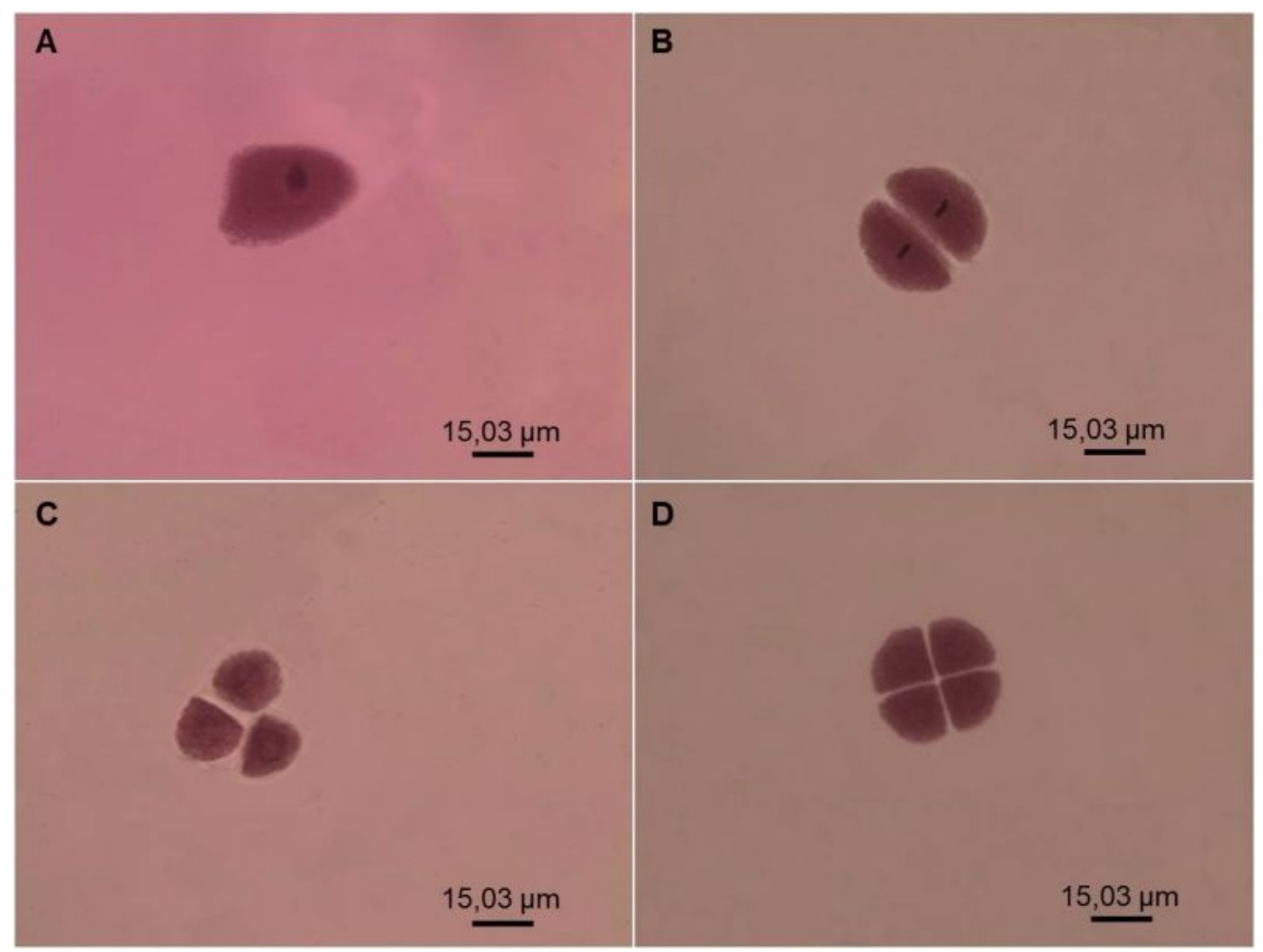

FIGURA 3. Produtos pós-meióticos do híbrido simples 2B810 PW (Dow) (Zea mays). (A) Mônade; (B) Díade; (C) Tríade; (D) Tétrade. Barra 15,03 $\mu \mathrm{m}$. Fonte: os autores.

Os resultados da ANOVA obtidos para a viabilidade polínica do milho (Híbrido simples 2B810 PW (Dow)) indicam significância no nível analisado (Tabela 1).

TABELA 1- Análise de variância (ANOVA) para os testes colorimétricos do híbrido simples 2B810 PW (Dow).

\begin{tabular}{ccc}
\hline Fonte de Variação & GL & QM \\
\hline Corantes & 3 & $0,10076^{*}$ \\
Erro & 28 & 0,002282 \\
CV $(\%)$ & 3,37 & \\
Média Geral & 97,33 & \\
\hline
\end{tabular}

*Significativo a 1\% pelo teste F; CV: Coeficiente de variância; QM: Quadrado Médio e GL: Grau de liberdade. 
Os quatro corantes utilizados na estimativa da viabilidade polínica apresentaram médias acima de 96\% (Tabela 2), o que, segundo Souza et al. (2002), em estudos com Passiflora edulis, é um alto percentual de viabilidade (acima de $70 \%$ ). Os autores destacam ainda que quanto mais alto a percentagem de grãos de pólen viáveis, maior será o índice de fertilização da espécie (SOUZA et al., 2002), por isso estudos como este são importantes para o melhoramento genético de plantas.

TABELA 2 - Média de pólens viáveis do híbrido simples 2B810 PW (Dow) com os corantes: reativo de Alexander, carmim acético $2 \%$, lugol e sudan IV.

\begin{tabular}{cc}
\hline Corantes & Médias \\
\hline Reativo de Alexander & $98,67 \mathrm{a}$ \\
Carmim Acético 2\% & $97,58 \mathrm{ab}$ \\
Lugol & $96,79 \mathrm{ab}$ \\
Sudan IV & $96,29 \mathrm{~b}$ \\
\hline
\end{tabular}

Os corantes utilizados neste estudo (reativo de Alexander, carmim acético $2 \%$, lugol e sudan IV) foram eficientes na distinção entre polens viáveis e inviáveis do milho híbrido simples 2B810 PW (Dow) (Zea mays), conforme demonstrado na Figura 4.

O reativo de Alexander é uma solução tripla composta pelos corantes: verde malaquita, fucsina ácida e orange $\mathrm{G}$. O verde malaquita cora a parede celular de verde, enquanto a fucsina ácida cora o protoplasma de vermelho/púrpura, dessa forma, o grão de pólen inviável cora-se todo de verde, por não apresentar protoplasma (ALEXANDER, 1969), como é possível observar na Figura 4A. Já o carmim acético indica a integridade cromossômica, corando os grãos de pólen viáveis por meio da coloração rosa forte do protoplasma (PAGLIARINI; POZZOBON, 2004), conforme Figura 4B.

Os corantes lugol e sudan IV coram substâncias presentes nos grãos de pólen maduros, como amido e lipídios, respectivamente, e são utilizados em alguns estudos como indicativos de viabilidade polínica (ARENAS-DE-SOUZA et al., 2014; TIAGO et al., 2014; SCHMITT et al., 2015; GIBBERT et al., 2017; RAMOS et al., 2017; LIMA et al., 2018). Quando o grão de pólen é amiláceo, o corante Lugol reage com a presença de amido, corando os grãos de pólen de marrom (BAKER; BAKER, 1979) como é possível observar na Figura 4C. Já o corante Sudan IV reage com a presença de lipídeos, então cora os grãos de pólen com uma cor avermelhada (DAFNI, 1992), conforme Figura 4D.

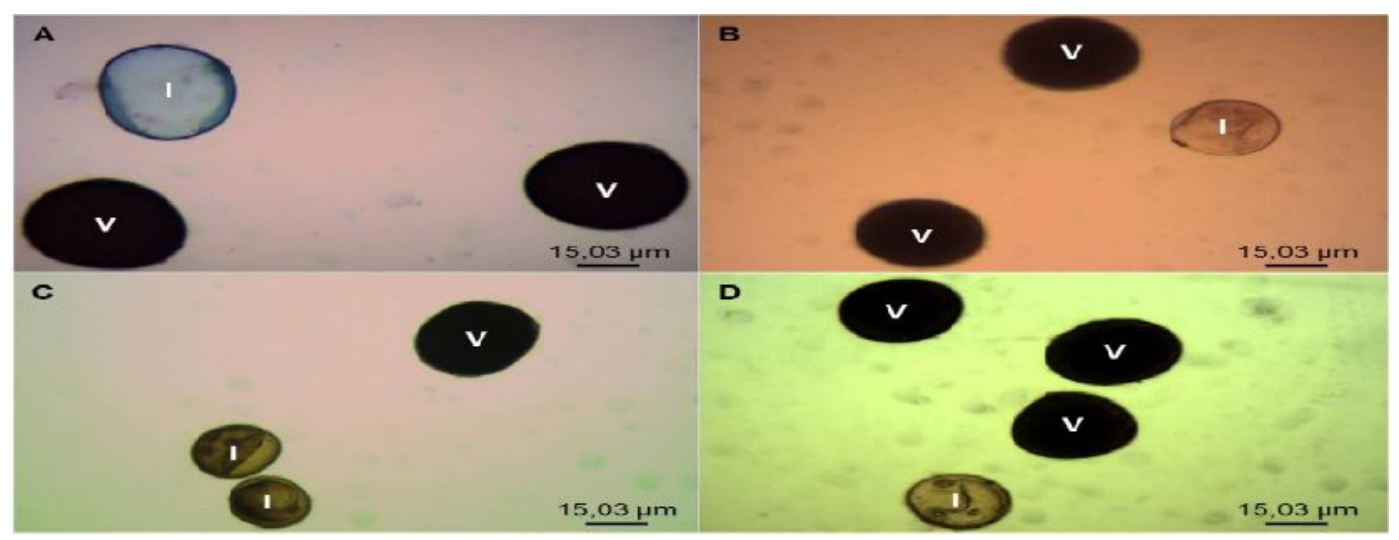


FIGURA 4 - Grãos de pólen viáveis (V) e inviáveis (I) do híbrido simples 2B810 PW (Dow) (Zea mays). (A) reativo de Alexander; (B) carmim acético 2\%; (C) lugol e (D) sudan IV. Fonte: os autores.

\section{CONCLUSÃO}

O milho híbrido simples 2B810 PW (Dow) (Zea mays) apresentou padrão meiótico estável $(\mathrm{IM}=85 \%)$ e alto percentual de grãos de pólen viáveis $(>96 \%)$, podendo ser utilizado como testemunha em ensaios e/ou teste de progênies em programas de melhoramento genético.

\section{REFERÊNCIAS}

ALEXANDER, M. P. Differential staining of aborted and nonaborted pollen. Stain Teh, v. 44, n. 3, p. 117-122, 1969. Disponível em: < https://www.tandfonline.com/doi/abs/10.3109/10520296909063335>. doi: $10.3109 / 10520296909063335$

ALMEIDA, C.; AMARAL, A. L.; BARBOSA NETO, J. F.; SERENO, M. J. C. M. Conservação e germinação in vitro de pólen de milho (Zea mays subsp. mays). Brazilian Journal of Botany, v. 34, n. 4, 2011. Disponível em: $<$ http://www.scielo.br/scielo.php?script=sci_arttext\&pid=S010084042011000400003>. doi: 10.1590/S0100-84042011000400003

ARENAS-DE-SOUZA, M. D.; SILVEIRA, G. F.; SILVA, M. S. A.; KARSBURG, I. V. Estimativa da viabilidade polínica em indivíduos de Tabebuia impetiginosa e Tabebuia chrysotricha (Mart. ex. DC.) standl. (Bignoniaceae) através de métodos citoquímicos. Enciclopédia Biosfera, v. 10, n. 18, p. 3864-3871, 2014. Disponível em:

<http://www.conhecer.org.br/enciclop/2014a/MULTIDISCIPLINAR/estimativa.pdf>.

BAKER, H. G.; BAKER, I. Starch in angiosperm pollen grains and its evolutionary significance. American Journal of Botany, v. 66, n. 5, p. 591-600, 1979. Disponível

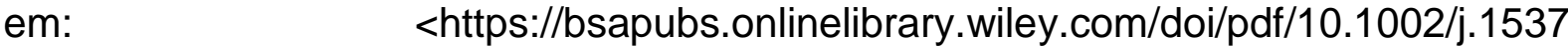
2197.1979.tb06262.x>. doi: 10.1002/j.1537-2197.1979.tb06262.x

BARROS, J. F. C.; CALADO, J. G. C. A Cultura do Milho. Escola de Ciências e Tecnologia. Departamento de Fitotecnia. Évora: Universidade de Évora, 52p. 2014. Disponível em: <https://dspace.uevora.pt/rdpc/bitstream/10174/10804/1/Sebentamilho.pdf>.

BRAMBATTI, A.; BRAMMER, S. P.; WIETHÖLTER, P.; JUNIOR, A. N. Estabilidade genética em triticale estimada pela viabilidade polínica. Arquivos do Instituto Biológico, v. 83, p. 01-07, 2016. Disponível em: <http://www.scielo.br/scielo.php?pid=S180816572016000100234\&script=sci_abstra t\&tlng=pt>. doi: 10.1590/1808-1657000802014

CONAB - Companhia Nacional de Abastecimento . Produção de milho no Brasil 17/18. 2018. Disponível em: <https://www.conab.gov.br/info-agro/safras/graos>. Acesso em: 17 jan. 2019. 
CRUZ, C. D. GENES - a software package for analysis in experimental statistics and quantitative genetics. Acta Scientiarum Technology, v. 35, n. 3, p. 271-276, 2013. Disponível em:

em: $\quad<$ http://www.scielo.br/scielo.php?pid=S1807-

$86212013000300001 \&$ script=sci_abstract\&tlng $=$ pt $>$.

doi: 10.4025/actasciagron.v35i3.21251.

DAFNI, A. Pollination Ecology: A Practical Approach. New York, Oxford: University press, 1992. 250p.

DAVIDE, L. M. C.; PEREIRA, R. C.; ABREU, G. B.; SOUZA, J. C.; PINHO, E. V. R. V. Viabilidade de pólen de milho em diferentes períodos de armazenamento em baixa temperatura. Revista Brasileira de Milho e Sorgo, v. 8, n. 2, p. 199-206, $2009 . \quad$ Disponível em: <http://rbms.cnpms.embrapa.br/index.php/ojs/article/view/281/pdf_168>.

FAVARATO, L. F.; SOUZA, J. L.; GALVÃO, J. C. C.; SOUZA, C. M.; GUARCONI, R. C.; BALBINO, J. M. S. Crescimento e produtividade do milho-verde sobre diferentes coberturas de solo no sistema plantio direto orgânico. Bragantia, v. 75, n. 4, 2016. Disponível em: <http://www.scielo.br/scielo.php?script=sci_arttext\&pid=S000687052016000400497>. doi: 10.1590/1678-4499.549

FLORA DO BRASIL 2020, em construção. Jardim Botânico do Rio de Janeiro. Disponível em: <http://floradobrasil.jbrj.gov.br/reflora/floradobrasil/FB87094>. Acesso em: 20 Dez. 2018.

GIBBERT, L. F.; RIBEIRO, R.; FERNANDES, S. C.; MELLO, V. S.; KARSBURG, I. $\mathrm{V}$. Viabilidade polínica de Syzygium malaccense por métodos colorimétricos. Agrarian Academy, v. 4, n. 7, 2017. Disponível em: <http://www.conhecer.org.br/Agrarian\%20Academy/2017a/viabilidade.pdf>. doi: 10.18677/Agrarian_Academy_2017a45

GUERRA, M.: SOUZA, M. J. Como observar cromossomos: um guia de técnicas em citogenética vegetal, animal e humana. Ribeirão Preto, SP: FUNPEC, 2002. $131 \mathrm{p}$.

HISTER, C. A. L.; TEDESCO, S. B. Estimativa da viabilidade polínica de araçazeiro (Psidium cattleianum Sabine) através de distintos métodos de coloração. Revista Brasileira de Plantas Medicinais, v. 18, n. 1, p. 135-141, 2016. Disponível em: <http://www.scielo.br/scielo.php?script=sci_arttext\&pid=S1516-

05722016000100135>. doi: 10.1590/1983-084X/15_081

IMEA - Instituto Mato-Grossense de Economia Agropecuária. Boletim semanal do milho. 11p. 2019. Disponível em: <http://www.imea.com.br/imea-site/relatoriosmercado-detalhe?c=3\&s=2>. Acesso em: 16 jan. 2019.

JORNALISMO AGROPECUÁRIO. Instituto Matogrossense de Economia Agropecuária. Entendendo o mercado do milho. 2015. 53p. Disponível em: < www.imea.com.br/upload/pdf/arquivos/Paper_jornalistas_Milho_AO.pdf>. Acesso em: 16 jan. 2019. 
LIMA, B. F. S.; HERMANN, F.; PARISOTTO, D. C.; NASCIMENTO, L. S. D.; KARSBURG, I. V. Índice meiótico e viabilidade polínica de Apeiba tibourbou Aubl. Agrarian Academy, v. 5, n. 9, p. 275-282, 2018. Disponível em: <http://www.conhecer.org.br/Agrarian\%20Academy/2018a/indice\%20meiotico.pdf>. doi: 10.18677/Agrarian_Academy_2018a27

LOVE, R. A. Estudos citológicos preliminares de trigos Riograndenses. Porto Alegre: Secretaria do Estado dos Negócios da Agricultura, Indústria e Comércio, 1949. 23p.

PAGLIARINI, M. S. Meiotic behavior of economically important plant species: the relationship between fertility and male sterility. Genetics and Molecular biology, v. 23, n. 4, p. 997-1002, 2000. Disponível em: <http://www.scielo.br/scielo.php?script=sci_arttext\&pid=S1415-47572000000400045 >. doi: 10.1590/S1415-47572000000400045

PAGLIARINI, M. S.; POZZOBON, M. T. II Curso de Citogenética Aplicada a Recursos Vegetais. Brasília: Embrapa Recursos Genéticos e Biotecnologia. 2004. 89p. (Documentos 154). Disponível em: <https://ainfo.cnptia.embrapa.br/digital/bitstream/CENARGEN/26521/1/doc154.pdf>.

QUEIROZ, T. N.; SILVA, N. T.; ALVES, S. M.; NASCIMENTO, P. N.; KARSBURG, I. V. Uso de diferentes corantes para a estimativa da viabilidade polínica e caracterização dos grãos de polens de sorgo granífero. Agrarian Academy, v. 5, n. 9, 2018. Disponível em: <http://www.conhecer.org.br/Agrarian\%20Academy/2018a/uso\%20de\%20diferentes. pdf>. doi: 10.18677/Agrarian_Academy_2018a32

RAMOS, L. P. N.; ANDRÉ, V. L. S.; MELLO, V. S.; DAMASIO, J. F.; KARSBURG, I. V. Estudo da viabilidade polínica de Myrciaria cauliflora (Mart.) O. Berg. por meio de distintos métodos de coloração. Agrarian Academy, v. 4, n. 8, p. 143-152, 2017. Disponível em: <http://www.conhecer.org.br/Agrarian\%20Academy/2017b/estudo\%20da\%20viabilid ade.pdf>. doi: 10.18677/Agrarian_Academy_2017b15

SANTOS, T. A.; TIAGO, P. V.; SCHMITT, K. F. M.; MARTINS, K. C.; ROSSI, A. A. B. Viabilidade polínica em Bertholletia excelsa Bonpl. (Lecythidaceae) baseada em diferentes testes colorimétricos. Enciclopédia Biosfera, v. 11, n. 22, 2015. Disponível em: <http://www.conhecer.org.br/enciclop/2015c/biologicas/viabilidade\%20polinica.pdf>.d doi: 10.18677/Enciclopedia_Biosfera_2015_030

SCHMITT, K. F. M.; PAULA, R. F.; MORENO, E. C.; TIAGO, A. V.; ROSSI, A. A. B. Uso de testes colorimétricos na avaliação da viabilidade polínica do urucum (Bixa orellana L.). Enciclopédia Biosfera, v. 11, n. 22, p. 2790-2797, 2015. Disponível em:

<http://www.conhecer.org.br/enciclop/2015c/agrarias/uso\%20de\%20testes\%20colori metricos.pdf> . doi: 10.18677/Enciclopedia_Biosfera_2015_243

SOUZA M. M.; PEREIRA, T. N. S.; MARTINS, E. R. Microsporogênese e microgametogênese associadas ao tamanho do botão floral e da antera e viabilidade 
polínica em maracujazeiro-amarelo (Passiflora edulis Sims f. flavicarpa degener). Ciência Agrotécnica, v. 26, n. 6, p. 1209-1217, 2002. Disponível em: $<$ http://www.editora.ufla.br/index.php/revistas/ciencia-e-agrotecnologia/artigospublicados>.

TIAGO, A. V.; ROCHA, V. D.; TIAGO, P. V.; LIMA, J. S.; ROSSI, A. A. B. Viabilidade polínica e receptividade estigmática em variedades de mandioca (Manihot esculenta Crantz). Enciclopédia Biosfera, v. 10, n. 1, 2014. Disponível em: < http://www.conhecer.org.br/enciclop/2014b/AGRARIAS/Viabilidade\%20Polinica.pdf>.

USDA - United States Department Agriculture. Agricultural Projections. 1p. 2018. Disponível em: https://www.fiesp.com.br/indices-pesquisas-e-publicacoes/saframundial-de-milho-2/attachment/file-20181212132426-boletimmilhodezembro2018/. Acesso em: 16 jan. 2019. 